\title{
PENGAMALAN NILAI-NILAI PANCASILA DALAM KEPRAMUKAAN
}

\author{
Remon Matius Richardo Sianturi \\ Politeknik Pembangunan Pertanian Yogyakarta-Magelang \\ rmnsianturi@gmail.com
}

\begin{abstract}
ABSTRAK
Praja Muda Karana atau bisa dibilang Pramuka adalah sebuah bagian dari pengembangan potensi diri dan pembentukan karakter bagi generasi milenial yang sesuai dengan Kode Kehormatan Pramuka yaitu Trisatya dan Dasadarma yang berlandaskan pada Pancasila dan UUD 1945. Penelitian ini akan berfokus pada pengamalan nilai-nilai Pancasila dalam kepramukaan di SMK Negeri 4 Sampit, pelaksanaan program kerja yang sudah ditetapkan oleh pembina atau dewan kerja ambalan, kegiatan kepramukaan disaat pandemi Covid-19 dan sebelum pandemi COVID-19, faktor-faktor apa saja yang akan terjadi di lapangan, dan pemecahan masalah terkait faktor-faktor apa saja yang akan terjadi di lapangan. Subjek penelitian ini adalah siswa, pembina pramuka, dan guru SMK Negeri 4 Sampit. Penelitian ini menggunakan metode kualitatif yaitu teknik pengumpulan data secara deskriptif.
\end{abstract}

Kata kunci: Pramuka, Kepramukaan, Pancasila, UUD 1945.

\begin{abstract}
Praja Muda Karana or you could say Pramuka is a part of developing self-potential and character building for the millennial generation in accordance with the Scout Code of Honor, namely Trisatya and Dasadarma which are based on Pancasila and the 1945 Constitution. This research will focus on the practice of Pancasila values in scouting. at SMK Negeri 4 Sampit, the implementation of work programs that have been determined by the supervisor or the troop work council, scouting activities during the Covid-19 pandemic and before the COVID19 pandemic, what factors will occur in the field, and solving problems related to the what factors will happen in the field. The subjects of this study were students, scout coaches, and teachers of SMK Negeri 4 Sampit. This research uses qualitative methods, namely descriptive data collection techniques.
\end{abstract}

Keywords: Scout, Scouting, Pancasila, UUD 1945.

\section{PENDAHULUAN}

Indonesia adalah negara kepulauan yang sangat beragam. Mulai dari suku, budaya, ras, bahasa, agama. Saat ini Indonesia memiliki 17 ribu pulau dengan 269 juta penduduk, dan 714 suku, serta 1100 bahasa (Wianto, 2020). Pancasila merupakan ideologi negara Indonesia yang dapat menyatukan keberagaman yang ada di Indonesia ini menjadi satu kesatuan yaitu bangsa Indonesia. Di dalamnya terkandung lima nilai penting sebagai pedoman bangsa Indonesia. Menurut (Anggraini 2018:1), Pancasila merupakan alat pemersatu bangsa yang kita tahu bahwa negara Indonesia memiliki suku, budaya, ras, dan agama serta kebiasaan yang berbeda merupakan prinsip bhineka tunggal ika yang menyebutkan bahwa berbeda-beda tetapi tetap satu jua, yang terikat dalam suatu negara yang disebut NKRI (Negara Kesatuan Republik Indonesia). Nilai-nilai yang terkandung di dalamnya sudah tentu menjadi kepribadian dan pandangan hidup masyarakat di seluruh indonesia. Pendidikan di sekolah menurut (Anggraini 2018:1) adalah pendidikan di sekolah telah menjadi suatu media yang sangat penting dalam upaya membentuk, menumbuh, dan mengembangkan nilai-nilai pancasila. Melalui macam-macam kegiatan baik intrakurikuler maupun ekstrakurikuler, siswa diajarkan untuk dapat mengamalkan 
apa yang terkandung dalam nilai-nilai Pancasila.

Persoalan nilai-nilai Pancasila menurut (Situru, 2019) berpendapat bahwa memudarnya nilai-nilai dalam Pancasila tergambar dari hilangnya semangat saling menghargai dan semangat gotong-royong. Anak-anak mulai tumbuh dengan kemajuan dan akses teknologi tanpa kontrol, gaya hidup hedonisme, maraknya berita hoax, dan kenakalan lainnya. Menurut (Muhtadi 2010:30-31) mengemukan bahwa bangsa indonesia masih dihadapkan pada berbagai permasalahan sosial dan moral seperti: masih tingginya kasus tindakan kekerasan, baik antar pelajar, masyarakat, keluarga, dan lingkungan sekitar, berkurangnya rasa hormat terhadap orang yang lebih tua, dan tidak memiliki tanggung jawab jika sudah melakukan kesalahan.

Berdasarkan uraian persoalan di atas penulis berpendapat bahwa sekolah juga mempunyai peran yang begitu penting dalam mengimplementasikan nilai-nilai Pancasila. Kegiatan yang dilakukan siswa baik di luar kelas (outdoor) maupun di dalam kelas (indoor) memiliki dampak yang positif pada pembentukan karakter, moral, dan kepribadian diri supaya menjadi lebih baik dan berguna bagi keluarga, masyarakat, dan lingkungan sekitar.

Pendidikan akan memproses segala bentuk pengetahuan yang ideal untuk menunjang perkembangan dan pembentukan karakter siswa. Menurut (Sasmito 2018:2), Proses pendidikan yang ideal adalah proses pendidikan yang memerhatikan perkembangan aspek kognitif, afektif dan psikomotorik siswa.
Ketiga aspek itu harus diimplementasikan pada semua mata pelajaran. Gerakan Pramuka dalam proses menyelenggarakan pendidikan kepramukaan berdasarkan Sistem Among. Sistem Among adalah cara pelaksanaan pendidikan di dalam gerakan pramuka. Sistem Among merupakan pendidikan yang dilaksanakan dengan cara memberikan kebebasan kepada peserta didik untuk dapat bergerak dan bertindak dengan leluasa, dengan sejauh mungkin menghidari unsur-unsur perintah keharusan, paksaan, dengan maksud untuk menumbuhkan dan mengembangkan rasa percaya diri, kreativitas dan aktivitas sesuai dengan aspirasi peserta didik (Kompasiana, 2018). Dengan menerapkan prinsip dasar kepramukaan dan metode kepramukaan, yang disesuaikan dengan keadaan, kepentingan, perkembangan bangsa dan masyarakat Indonesia.

Menurut (Gischa, 2020), Pramuka adalah singkatan dari Praja Muda Karana yang merupakan organisasi atau gerakan kepramukaan. Pramuka adalah sebuah organisasi yang merupakan tempat proses pendidikan kepramukaan yang dilaksanakan di Indonesia guna membentuk karakter, moral, dan kepribadian diri. Pramuka penting untuk menerapkan nilai-nilai Pancasila menurut (Surono 2017:24), kegiatan ekstrakurikuler Pramuka diharapkan dapat memberikan pengaruh terhadap perkembangan jiwa siswa, dengan mengikuti kegiatan pramuka siswa dapat membangun sikap nasionalisme yaitu sikap kepemimpinan, keberanian, tanggung jawab, serta cinta tanah air yang berkaitan dengan pembentukan moral dan karakter. Hal ini sesuai dengan teori yang dikemukakan oleh (Djoyomartono 2009:11) bahwa sikap 
nasionalisme bearti upaya seseoarang untuk mengembangkan anak akan pentingnya memiliki ide dan perilaku yang sesuai dengan jiwa nasionalisme Indonesia dan berjiwa Pancasila.

\section{METODE}

\section{Jenis Penelitian}

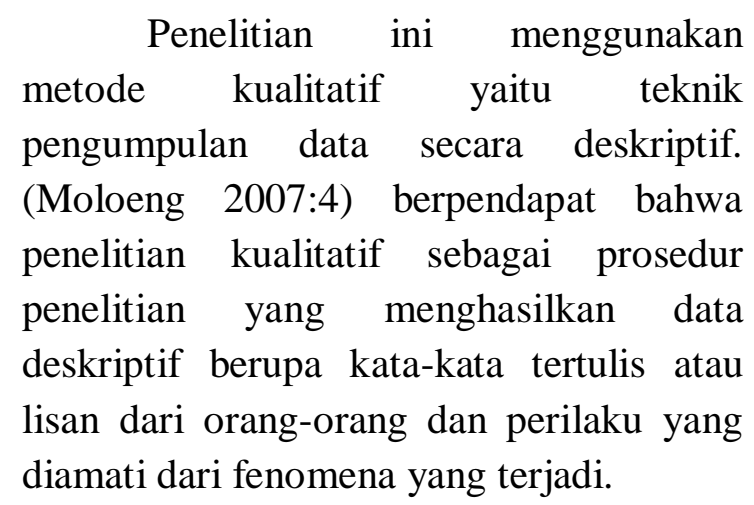

\section{Waktu dan Tempat Penelitian}

Penelitian ini dilakukan di sekolah SMK Negeri 4 Sampit pada tanggal 29 Januari 2021, di Kabupaten Kotawaringin Timur Provinsi Kalimantan Tengah. Waktu penelitian ini sudah dilakukan sejak tahun 2019 sampai 2020. Di mana penulis sudah mengalami dan merasakan arti dari nilai-nilai Pancasila dalam kegiatan kepramukaan dan didokumentasi dijurnal online agar setiap orang yang membaca bisa menjadi pelajaran dan motivasi ke depannya, bagaimana menerapkan nilainilai pancasila dalam kegiatan kepramukaan baik di luar ruangan (outdoor) maupun di dalam ruangan (indoor).

\section{Subjek Penelitian}

Pada pengumpulan data yang berupa wawancara dilakukan secara online yaitu penulis dengan pembina pramuka, penulis dengan guru SMK Negeri 4 Sampit, dan penulis dengan siswa, hal ini karena penulis yakin bahwa yang diwawancarai mempunyai integritas yang baik dan mempunyai pengalaman yang harus diceritakan. Di mana penulis akan melontarkan pertanyaan seputar pramuka dan bagaimana mengantisipasi kegiatan disaat pandemi COVID-19 dan sebelum pandemi COVID-19.

\section{Teknik Pengumpulan Data}

Analisis data yang digunalan adalah teknik pengumpulan data secara deskriptif dengan bentuk wawancara. Menurut Moleong (2007:11), penelitian deskriptif menegaskan pada data berupa kata-kata, gambar, dan bukan angka-angka yang disebabkan oleh adanya penerapan metode kualitatif.

Ada pun pengambilan data menggunakan dokumentasi artinya pengumpulan data dengan mencatat semua informasi yang diperoleh dari arsip yang terkait dengan kegiatan pramuka seperti program kerja yang sudah disiapkan Dewan Kerja Ambalan SMK Negeri 4 Sampit. metode dokumentasi bearti cara mengumpulkan data dengan mencatat data-data yang sudah ada (Riyanto 2010:103).

\section{PEMBAHASAN}

Berdasarkan wawancara penulis dengan narasumber bahwa pengamalan nilai-nilai pancasila dalam kepramukaan di SMK Negeri 4 Sampit, yang mana dijelaskan bahwa landasan dari Pramuka itu sendiri mengambil dari pancasila dan 
UUD 1945 untuk menumbuhkan dan mengembangkan karakter, cinta tanah air, patriotisme, dan nasionalisme sesuai dari Kode Kehormatan Pramuka. Analisis dari hasil wawancara dilakukan dengan mencocokkan data hasil wawancara dengan narasumber yang telah dideskripsikan dengan kenyataan yang ada di lapangan, Sehingga dengan demikian dapat ditemukan kebenaran jawabannya. Dalam analisis ini penulis mendapatkan penjabaran tentang arti dari nilai-nilai Pancasila dalam kepramukaan di SMK Negeri 4 Sampit antara lain:

1. Ketuhanan yang Maha Esa

Bersinambungan dengan poin Dasadarma ke 1 dan 10, yang mana pengamalan nilai-nilainya seperti contoh, pada saat kegiatan Pramuka di SMK Negeri 4 Sampit di waktu sore (jam 15.00), mereka tetap melaksanakan ibadah masingmasing. pada saat awal masuk ke ruangan ijin dan mengucapkan salam serta selalu mengucapkan kebaikan dalam hati pikiran perkataan dan perbuatan.

2. Kemanusiaan yang adil dan beradab

Masuk ke Dasadarma ke 2, 3, dan 5. Contohnya pada saat kegiatan Pramuka disini ditanamkan cinta kepada alam seperti gotong royong dan bersihbersih halaman serta tempat ruangan kegiatan pada saat Pramuka itu berlangsung serta kepada sesama teman-teman saling mencintai dan menghormati dengan cara saling memanggi dengan panggilan kakak. Diajarkan menjadi pemimpin atau petugas pada saat upacara dan apel disitu mengajarkan mereka agar bisa menjadi patriot selalu mengutamakan 7S (Salam, sapa, senyum,santun sopan, semngat sepenuh hati). Saling tolong menolong dalam kehidupan karena kalo bukan teman sendiri siapa lagi apabila ada kesusahan contohnya seperti saudara kita di banjar banjir, Pramuka turun tangan untuk menjual produk atau terjun kelapangan untuk pengumpulan dana.

3. Persatuan indonesia

Poin Dasadarma ke 6 dan 7. Dalam persatuan di dalam Pramuka SMKN 4 Sampit selalu hemat dalam mengelola keuangan dan bisa membuka kewirausahaan (jual produk) uangnya di kelola agar lebih baik. cermat dalam melihat situasi dan kodisi dan selalu bersahaja atau berusaha dalam melakukan sesuatu berencana agar sesuai dngan tujuan pencapaian kegiatan.

4. Kerakyatan yang dipimpin oleh hikmat kebijaksanaan dalam permusyawaratan dan perwakilan

Sesuai dengan poin 4 dan 9. Selalu melakukan musyawarah rapat ambalan sekurangnya 1 bulan 1 kali untuk membahas program dari kinerja dalam berkegiatan. Patuh kepada pemimpin dari ambalan pembina dan pihak sekolah selalu mengikuti prosedur yang ditetapkan. Bertanggung 
jawab dan dapat dipercaya. Selalu apa pun yang dilakukan pemimpin atau anggotanya menekankan tanggung jawab berani bertindak berani tanggung jawab dan anak Pramuka selalu diberi kepercayaan atas garda di depan untuk pembentukan karakter yang baik.

5. Keadilan sosial bagi seluruh rakyat indonesia

Masuk ke poin Dasadarma ke 8. Disiplin berani dan setia akan keadilan sosial seperti disiplin dalam mengelola kegiatan dalam pembagian kelompok harus adil yang mana yang aktif dan tidaknya semuanya dicampur agar kesemerataan untuk kelompok, selalu disiplin untuk menerapkan peraturan di skolahan untuk kebaikan bersama serta setia dalam jiwa korsa (kebersamaannya).

Pada pelaksanaan program kerja yang ditetapkan pembina Pramuka atau dewan kerja ambalan adalah latihan rutin, rapat anggota dan ambalan, berkunjung kepada sesama teman anggota dari ambalan Pramuka. Kegiatan yang pernah dilaksanakan antara lain latihan rutin (1 bulan sekali di sekolahan), musyawarah ambalan dan pelantikan sangga inti, baksos penggalangan dana untuk saudara di kalsel, pembuatan dan menjual produk, belajar melalui daring (online), Mengikuti webinar Pramuka di luar, kumpul bersama tahun baruan untuk mempererat persaudaraan, lomba foto kreatif pada saat pandemi COVID-19 antar anggota dan sanggah inti, kegiatan dianpindat geladian pemimpinan satuan di kwarcab serta tetap mengikuti protokol kesehatan.
Kegiatan kepramukaan disaat pandemi COVID-19 dan sebelum pandemi COVID-19 bisa melalui pembelajaran jarak jauh (online) dan pembelajaran tatap muka (offline). Dalam kegiatan melalui pembelajaran jarak jauh langkah awalnya dari pembelajaran adalah mendownload zoom, googlemeet, atau grup whatsapp yang sudah disepakati bersama. Siswa SMK Negeri 4 Sampit diharapkan menaati peraturan dalam memakai seragam, menyapa, hingga memasuk materi. Materi yang dipelajari adalah sesuai dengan Syarat-syarat Kecakapan Umum (SKU) dan Syarat-syarat Kecakapan Khusus (SKK). Pada pembelajaran tatap muka siswa SMK Negeri 4 Sampit akan bertemu pembina pramuka tetapi dalam kondisi sehat, dibatasi siswa nya setiap ada kegiatan di luar, dan selalu menjaga protokol kesehatan. Dalam rangka pandemi COVID-19 siswa SMK Negeri 4 Sampit aktif dalam mengikuti webinar atau seminar online melalui zoom guna mendapatkan ilmu, pengetahuan, pengalaman, dan pertemanan.

Dalam kegiatan sebelum pandemi COVID-19 siswa yang ditingkat penegak akan melakukan dan memenuhi Sistem Tanda Kecakapan Gerakan Pramuka, yaitu Syarat-syarat Kecakapan Umum (SKU) untuk mencapai tanda kecakapan umum dan Syarat-syarat Kecakapan Khusus (SKK) untuk mencapai tanda kecakapan khusus. Tingkat kecakapan umum Pramuka penegak berupa tanda pundak yang dibuat dari kain dengan warna dasar hijau tua. Tulisan dan gambar pada tanda tersebut dibuat dengan sulaman atau logam berwarna kuning emas. Berbentuk trapesium, berwarna dasar hijau tua dengan panjang sisi $5 \mathrm{~cm}$, sisi atas $4 \mathrm{~cm}$ 
dan panjang kaki miring kiri dan kanan masing-masing $7,5 \mathrm{~cm}$, didalamnya terdapat gambar bintang sudut lima di bawahnya terdapat sepasang tunas kelapa yang berlawanan arah dan di bawah tunas kelapa terdapat tulisan BANTARA atau LAKSANA. Menurut (Balai Penerbit Gerakan Pramuka 2007:13), Tingkat kecakapan khusus Pramuka penegak adalah kecakapan, kepandaian, kemahiran, ketangkasan, dan keterampilan di bidang tertentu yang dimiliki Pramuka Penegak sesuai dengan minat dan bakatnya. SKK adalah syarat-syarat kecakapan sesuai dengan minat dan bakat Penegak yang harus dipenuhi untuk mendapatkan TKK. TKK merupakan tanda kecakapan bagi Pramuka Penegak setelah menempuh syarat-syarat khusus sesuai dengan minat dan bakatnya.

Dalam melaksanakan pembentukan karakter dan mengimplementasikan nilainilai Pancasila di SMK Negeri 4 Sampit tentunya memiliki faktor yang mendukung berjalannya tujuan mengimplementasikan nilai-nilai Pancasila. Faktor yang mendukung berjalannya tujuan mengimplementasikan nilai-nilai Pancasila adalah motivasi dan komunikasi antara siswa ke pembina pramuka atau siswa ke kakak pramuka atau siswa ke siswa. Faktor pendukung inilah yang akan membentuk karakter dan menerapkan nilai-nilai pancasila dalam kehidupan sehari-hari.

Ada pun faktor yang menghambat dalam mengimplementasikan nilai-nilai Pancasila adalah Pada saat dilapangan kendala cuaca biasanya bisa meminjam ruangan untuk berkegiatan di dalam kelas dalam bentuk penjelasan teori dan praktek seadanya. Pada saat pandemi ini sangat kurang efektif untuk dirumah berkegiatannya (belajar daring) karena jika kegiatan secara online banyak yang tidak mengikuti alasan jaringan atau paketannya. Solusinya kita tetap adakan seadanya walaupun tidak terlalu banyak yang respon setidaknya dari ambalan berusaha untuk memberikan terbaik urusan hasil bisa di evaluasi agar bisa mencari cara atau solusi lain. Sumber daya manusia yang kurang aktif sehingga berkegiatan kurang maksimal, misalnya mau berkegiatan banyak yang ikut tapi yang ikut rapat sedikit dan pada saat dilapangan (kegiatan) banyak yang muncul padahal yang sedikit dirapatkan itu sudah merencanakan sedemikian rupa, tapi yang tidak rapat kurang memahami teknis sehingga banyak yang meleset dari perencanaan. Minat Pramuka dan kedisiplinan. Di lapangan kadang tidak terlalu banyak yang hadir karena kurangnya minat sehingga kurang disiplin sehingga yang ada saja disiplinkan setelah itu, Minggu selanjutnya beda lagi orangnya begitu seterusnya jadi, bisa menyesuaikan sja yang penting dari sangga inti dan Ambalan lebih disiplin dan diterapkan peraturan untuk semuanya.

Faktor-faktor yang terjadi di lapangan sebelum pandemi COVID-19 adalah situasi dalam lapangan, apakah kondisinya hujan atau tidak. Faktor lainnya adalah berbagai macam kegiatan di sekolah misalnya bersih-bersih lapangan, persiapan lomba, dll. Pemecahan masalah terkait faktor-faktor yang terjadi di lapangan adalah melakukan kegiatan di dalam ruangan yang sudah disiapkan dewan kerja ambalan misalnya melakukan syarat-syarat kecakapan umum. Jika siswa sudah mulai bosan atau lelah, dewan kerja ambalan akan memberikan permainan atau 
tantangan untuk siswa guna untuk melatih percaya diri dan membentuk karakter.

Penanaman nilai-nilai Pancasila dalam rangka membangun persatuan dan kesatuan bangsa, memperkuat karakter generasi muda, dan mengimplementasikan nilai-nilai Pancasila. Nilai-nilai Pancasila ditanamkan pada kegiatan kepramukaan dengan metode keteladanan, penanaman kedisiplinan, pembiasaan, menciptakan suasana kondusif, integrasi, dan internalisasi. Setiap manusia mempunyai karakter yang berbeda-beda, karakter sudah ada sejak lahir atau pun sifat bisa sama dengan orang tua. Karakter juga ada yang karakter negatif maupun yang positif. Cara merubah karakter negatif kepositif di dalam lingkungan sekolah adalah menerapkan kegiatan ekstrakurikuler pramuka di sekolah guna untuk menanamkan nilai pendidikan karakter disiplin, jujur, religius, toleransi, kerja keras, mandiri, tanggung jawab, dan segalanya (Elisa 2019:115-116).

\section{KESIMPULAN}

Kepramukaan adalah proses pendidikan di luar lingkungan sekolah dan keluarga yang diselenggarakan dalam kegiatan yang menarik, menyenangkan, sehat, teratur, terarah, dan praktis. Pengamalan nilai-nilai pancasila dalam kepramukaan di SMK Negeri 4 Sampit, yang mana dijelaskan bahwa landasan dari Pramuka itu sendiri mengambil dari pancasila dan UUD 1945 untuk menumbuhkan dan mengembangkan karakter, cinta tanah air, patriotisme, dan nasionalisme sesuai dari Kode Kehormatan Pramuka. Kegiatan kepramukaan disaat pandemi COVID-19 dan sebelum pandemi COVID-19 bisa melalui pembelajaran jarak jauh (online) dan pembelajaran tatap muka (offline). Faktor yang mendukung berjalannya tujuan mengimplementasikan nilai-nilai Pancasila adalah motivasi dan komunikasi antara siswa ke pembina pramuka atau siswa ke kakak pramuka atau siswa ke siswa. Faktor pendukung inilah yang akan membentuk karakter dan menerapkan nilai-nilai pancasila dalam kehidupan sehari-hari.

\section{DAFTAR PUSTAKA}

Anggadiredja, Jana T dkk. 2011. "Panduan Penyelesaian Syarat Kecakapan Umum Pramuka Golongan Penegak" dalam Syarat Kecakapan Umum (Ed. Susi Yuliati dan Deden Syefruddin). Jakarta: Kwartir Nasional Gerakan Pramuka.

Anggraini, Rini. 2018. Program Kepramukaan Sebagai Upaya Menumbuhkan Nilai-Nilai Pancasila Kepada Siswa Sekolah Menengah Kejuruan. Skripsi. Jakarta: Prodi Pendidikan Pancasila dan Kewarganegaraan Fakultas Ilmu Sosial dan Politik Universitas Negeri Jakarta.

Balai Penerbit Gerakan Pramuka. 2007. Petunjuk Penyelenggaraan Kecakapan Khusus tahun 1976. Jakarta: Kwartir Nasional Gerakan Pramuka. 2007. Syarat-syarat dan Gambar Tanda Kecakapan Khusus Gerakan Pramuka tahun 
1979. Jakarta: Kwartir Nasional Gerakan Pramuka.

Elisa dkk. 2019. "Penanaman Nilai-Nilai Pendidikan Karakter Siswa melalui Kegiatan Ekstrakurikuler Pramuka”. Semarang: Universitas PGRI Semarang.

Gischa, Serafica. 2020. "Apa Arti Kata Pramuka". Diakses dari https://www.kompas.com/skola/re ad/2020/07/28/142926569/apaarti-kata-pramuka?page $=$ all pada 29 Januari 2021.

Gifari, Aufan. 2018. "Implementasi NilaiNilai Pancasila dalam Menumbuhkan Nasionalisme di Lingkungan Sekolah Islam (Studi di Mts AL Falah Pancor Dao Lombok Tengah". NTB: Universitas Mataram.

Hapsari, Lysa. 2013. "Peran Pembelajaran PKn dan Kegiatan Kepramukaan dalam Membentuk Karakter Siswa di Man 1 Yogyakarta". Yogyakarta: Universitas Negeri Yogyakarta.

Kompasiana.com. 2018. "Sistem Among dalam Pramuka". Diakses dari https://www.kompasiana.com/hen di1516/5c0195c5677ffb471d5bcf e3/sistem-among-dalampramuka?page $=$ all $\quad$ pada 28 Januari 2021.

Moleong, J .2007. Metodologi Penelitian Kualitatif. Bandung : PT. Remaja Rosdakarya.

Muhtadi, Ali. 2010. "Strategi Implikasi Pendidikan Budi Pekerti yang
Efektif di Sekolah". Yogyakarta: Dinamika Pendidikan.

Riyanto, Yatim. 2010. Metode Penelitian Pendidikan. Surabaya: SIC.

Sasmito, Yogi Aji. 2018. "Implementasi Nilai-Nilai Pancasila untuk Menumbuhkan Rasa Nasionalisme di SDN 3 Ngemplak. Surakarta: Universitas Muhammadiyah Surakarta.

Situru, Roberto Salu. 2019. "Pancasila dan Tantangan Masa Kini”. Makasar: Universitas Kristen Indonesia Toraja.

Surono, Kabul Aris. 2017. "Penanaman Karakter dan Rasa Nasionaisme pada Kegiatan Ekstrakurikuler Pramuka di SMP N 4 Singorojo. Kendal: Indonesia Journal of Conservation.

Wianto, Vincentius Christian Aji. 2020. "Pancasila Sebagai Alat Pemersatu Bangsa". Diakses dari https://binus.ac.id/characterbuilding/pancasila/pancasilasebagai-alat-pemersatu-bangsa/ pada 02 Februari 2021. Jakarta: Binus University.

\section{UCAPAN TERIMA KASIH}

Puji syukur kepada Tuhan Yang Maha Esa yang telah memberikan rahmat dan karunia-Nya kepada penulis, Sehingga penulis bisa menyelesaikan jurnal Pengamalan Nilai-Nilai Pancasila dalam Kegiatan Kepramukaan dengan baik. Atas dukungan moral dan materi yang diberikan 
dalam penyusunan jurnal ini, maka penulis mengucapkan terima kasih kepada Kakak Maulana Ahmad Syifa sebagai pembina Pramuka (satuannya) di lapangan SMK Negeri 4 Sampit, Kakak Pramuka SMK Negeri 4 Sampit, Ketua Ambalan Putra yang bernama Rizky Jaka Mahendra dan Ketua Ambalan Putri yang bernama Novianna Rahmadhanti, Dewan Kerja Ambalan, dan siswa/ siswi SMK Negeri 4 Sampit yang telah membantu menyelesaikan jurnal ini. Terlepas dari semua itu, saya menyadari sepenuhnya bahwa masih ada kekurangan baik dari segi susunan kalimat maupun tata bahasanya. Oleh karena itu saya menerima segala saran dan kritik dari pembaca agar saya dapat memperbaiki jurnal ini dan masukan-masukan yang sifatnya membangun sangat diharapkan. Harapan saya semoga jurnal ini dapat menambah pengetahuan dan pengalaman bagi para pembaca, untuk ke depannya dapat memperbaiki bentuk maupun menambah isi jurnal agar menjadi lebih baik lagi.

\section{TENTANG PENULIS}

Remon Matius Richardo Sianturi bisa dipanggil Remon. Lahir di Sampit, 13 Juli 2002. Merupakan anak kedua dari dua bersaudara. Remon masih menempuh pendidikan di Politeknik Pembangunan Pertanian Yogyakarta-Magelang Jurusan Pertanian Program Studi Teknologi Benih Semester 1. Motivasi untuk kita semua, waktu adalah keuntungan. 